\title{
Divergência genética entre híbridos de milho em condições de deficiência hídrica
}

\section{Aurélio Vaz de Melo', Valdere Martins dos Santos, Tiago Mateus Lopes ${ }^{1}$, Marilene Alves Ramos Dias ${ }^{1}$, Helber Veras Nunes ${ }^{2}$}

${ }^{1}$ Fundação Universidade Federal do Tocantins, Campus Universitário de Gurupi, Gurupi, Tocantins, Brasil. E-mail: vazdemelo@mail.uft.edu.br, valderemartins25@hotmail.com,ogaitbigode@bol.com.br, maridiasgpi@hotmail.com

${ }^{2}$ Instituto Federal do Tocantins, Campus Universitário de Gurupi, Gurupi, Tocantins, Brasil. E-mail: helberveras@ yahoo.com.br Recebido: 10/12/2017; Aceito: 01/04/2019.

\section{RESUMO}

$\mathrm{Na}$ obtenção de cultivares adaptados às condições edafoclimáticas de uma determinada região ou estresse específico, é importante que as diferenças entre os cultivares estejam sob controle genético. Diante disso, objetivou-se determinar a divergência genética entre híbridos experimentais de milho (Zea mays) quanto à resistência a condições de seca. Para tal, realizou-se um ensaio em ambiente protegido no delineamento experimental em blocos casualizados, com quatro repetições, sendo os tratamentos dispostos em um arranjo fatorial 28 x 2, em que 28 híbridos experimentais de milho, oriundos do Programa de melhoramento da UFT, foram avaliados em duas condições hídricas (a $20 \%$ e a $80 \%$ da CC) utilizando metodologia adaptada do lisímetro. Decorridos 20 dias da emergência, foram avaliadas 15 características. Na análise de divergência genética, empregou-se o método de agrupamento de otimização de Tocher e o método hierárquico do vizinho mais próximo, utilizando a distância generalizada de Mahalanobis (D2) como medida de dissimilaridade e o critério de Singh para quantificar a contribuição relativa das características na divergência. As medidas de dissimilaridade genética, estimadas pela distância de Mahalanobis, apresentaram magnitudes de 1,64 a 40,54 no ambiente 20\% CC, e de 1,52 a 43,46 no ambiente $80 \%$ CC, indicando a presença de variabilidade genética na população. Com isso, sugere-se a combinação dos híbridos 6 e 10 no ambiente $20 \%$ CC, e entre 1 e 17 no ambiente $80 \%$ CC para a obtenção de híbridos com maior efeito heterótico.

Palavras-chave: Zea mays (L), divergência genética, estresse hídrico, seleção de genitores.

\section{Genetic divergence between corn hybrids in conditions of water deficiency}

\section{ABSTRACT}

In obtaining cultivars adapted to the edaphoclimatic conditions of a specific region or specific stress, it is important that the differences between the cultivars are under genetic control. The objective of this study was to determine the genetic divergence between experimental maize hybrids (Zea mays) in terms of resistance to drought conditions. For this purpose, a randomized block design with four replicates was carried out in a protected environment. The treatments were arranged in a $28 \times 2$ factorial arrangement, in which 28 maize experimental hybrids from the UFT improvement program were evaluated in two water conditions (at $20 \%$ and $80 \%$ of the CC). Using adapted lysimeter methodology. Twenty days after the emergency, 15 characteristics were evaluated. In the analysis of genetic divergence, the Tocher optimization grouping method and the closest neighbor hierarchical method were used, using the generalized distance of Mahalanobis (D2), as a measure of dissimilarity and the criterion of Singh to quantify the relative contribution of characteristics in divergence. Genetic dissimilarity measurements, estimated by distance from Mahalanobis, showed magnitudes from 1.64 to 40.54 in the $20 \%$ CC environment, and 1.52 to 43.46 in the $80 \% \mathrm{CC}$ environment, indicating the presence of genetic variability in the population. Therefore, we suggest the combination of hybrids 6 and 10 in the environment $20 \%$ CC, and between 1 and 17 in the environment $80 \%$ CC to obtain hybrids with greater heterotic effect.

Keywords: Zea mays (L), genetic divergence, drought stress, selection of parents. 


\section{Introdução}

O Estado do Tocantins possui um grande potencial produtivo para o agronegócio, contendo, aproximadamente, 14 milhões de hectares agricultáveis. O milho é o terceiro cereal mais cultivado no Estado, apresentando uma grande expansão no território. Na safra 2017/2018, a área plantada foi de 52,9 mil hectares, com um aumento de 15,2\% em comparação à área plantada na safra 2016/2017, com 45,9 mil hectares (Conab, 2018).

Na região Norte do Brasil, ocorre um predomínio de clima seco aliado com altas temperaturas. Esses efeitos climáticos adversos influenciam diretamente o crescimento e o desenvolvimento das plantas, limitando a produção agrícola a nível mundial (Silva et al., 2011a). Para as próximas décadas, são previstas alterações climáticas globais que poderão alterar o regime de precipitação em várias regiões do Brasil, resultando no aumento de frequência de veranicos em algumas regiões produtoras (Domingues et al., 2011).

A cultura do milho (Zea mays L.) é particularmente sensível ao estresse hídrico, uma vez que esse fator causa redução da atividade fotossintética por meio da redução de assimilação de $\mathrm{CO}_{2}$ (Rahman et al., 2004). A deficiência hídrica causa alterações no crescimento vegetal, ocasionando a redução da área foliar, incremento do fechamento estomático, redução da transpiração e aceleração da senescência e da abscisão foliar, processos esses que dependem do genótipo, da duração e severidade do estresse, bem como do estádio de desenvolvimento das plantas (Taiz e Zeiger, 2009).

A adaptação de plantas a estresses abióticos como a seca constitui uma das alternativas para a redução de custos com irrigação (Bänzinger et al., 2000). Dessa forma, o melhor entendimento dos mecanismos envolvidos no metabolismo da planta em estresse, juntamente com o melhoramento genético, contribuirá para a obtenção de cultivares produtivos em condições de baixa disponibilidade hídrica no solo. Estudos têm relatado que inúmeras características fisiológicas podem ser utilizadas como ferramentas em programas de melhoramento visando a tolerância à deficiência hídrica (Gholamin e Khayatnezhad, 2011).

A divergência genética pode ser avaliada por meio de métodos preditivos ou quantificada por meio da realização de cruzamentos. Os métodos preditivos, se eficientes, são preferíveis em relação aos métodos quantitativos, uma vez que os primeiros evitam a realização de cruzamentos entre os inúmeros progenitores disponíveis para início do programa de melhoramento (Cruz e Regazzi, 2005).

Nesse contexto, a identificação da influência de cada característica na divergência genética entre cultivares é importante no direcionamento dos programas de melhoramento para obtenção de cultivares mais produtivos (Dotto et al., 2010), de forma que se objetivou com o presente trabalho estimar a divergência genética entre híbridos experimentais de milho (Zea mays) quanto à tolerância a condições de deficiência hídrica.

\section{Material e Métodos}

Os ensaios relativos às avaliações de genótipos experimentais de milho em condições de deficiência hídrica foram instalados na Estação Experimental da Universidade Federal do Tocantins - Campus Universitário de Gurupi, em Gurupi-Tocantins $(280 \mathrm{~m}$ de altitude, nas coordenadas $11^{\circ} 43^{\prime} 45^{\prime \prime} \mathrm{S}$ e $49^{\circ} 04^{\prime} 07^{\prime}$ W), no período de setembro a outubro 2012.

Os dados agroclimáticos foram obtidos da estação meteorológica da UFT, Campus de Gurupi, próximo do local do ensaio. Estes dados referem-se à temperatura máxima, média e mínima, umidade relativa e precipitação (Figura 1).

A semeadura foi realizada em 18 de setembro de 2012 em ambiente protegido, sendo o solo utilizado classificado como Latossolo Vermelho. A análise química do solo referente à camada superficial (0-20 $\mathrm{cm})$ foi realizada no Laboratório de Solos, Campus de Gurupi, apresentando as seguintes características químicas e físicas: $\mathrm{pH}$ em água $=5,6 ; \mathrm{P}=1,5 \mathrm{mg} \mathrm{dm}^{-3}$; $\mathrm{K}=27,6 \mathrm{mg} \mathrm{dm}^{-3} ; \mathrm{Ca}^{2+}=0,5 \mathrm{cmol}_{\mathrm{c}} \mathrm{dm}^{-3} ; \mathrm{Mg}^{2+}=0,2$ $\mathrm{cmol}_{\mathrm{c}} \mathrm{dm}^{-3} ; \mathrm{Al}^{3+}=0 \mathrm{cmol}_{\mathrm{c}} \mathrm{dm}^{-3} ; \mathrm{H}+\mathrm{Al}=3,1 \mathrm{cmol}_{\mathrm{c}} \mathrm{dm}^{-}$ 3; $\mathrm{SB}=0,8 \mathrm{cmol}_{\mathrm{c}} \mathrm{dm}^{-3} ; \mathrm{CTC}(\mathrm{t})=0,8 \mathrm{cmol}_{\mathrm{c}} \mathrm{dm}^{-3} ; \mathrm{CTC}$ (T) $=3,8 \mathrm{cmol}_{\mathrm{c}} \mathrm{dm}^{-3} ; \mathrm{V}=19,6 \% ; \mathrm{m}=0,0 \% ; \mathrm{MO}=$ 13,2\%; P $(\mathrm{Mel})=1,5 \mathrm{mg} \mathrm{dm}{ }^{-3} ;$ Areia: 43,1\%; Silte: $12,4 \%$; Argila: $44,5 \%$.

$\mathrm{O}$ delineamento experimental utilizado foi em blocos casualizados, com quatro repetições, sendo os tratamentos dispostos em um arranjo fatorial $28 \times 2$, em que 28 híbridos experimentais de milho foram avaliados em duas condições hídricas (a $20 \%$ e a $80 \%$ da CC). Cada parcela foi constituída por um vaso, com uma planta de milho. O solo foi colocado em sacos plásticos com volume de $3 \mathrm{dm}^{-3}$, nos quais foram realizados a calagem e a adubação fosfatada.

A correção da acidez do solo foi realizada de acordo com a recomendação para o Estado de Minas Gerais (Alves et al., 1999). A dose de $\mathrm{P}_{2} 0_{5}$ foi de $150 \mathrm{~kg} \mathrm{ha}^{-1} \mathrm{e}$ a fonte de $\mathrm{P}$ utilizada foi superfosfato triplo. A adubação de cobertura foi realizada ao $10^{\circ}$ dia de emergência, quando as plantas estavam no estádio fenológico V3, utilizando-se o adubo formulado de NPK (20-00-20), na dose de $450 \mathrm{~kg} \mathrm{ha}{ }^{-1}$. Os híbridos avaliados foram oriundos do Programa de melhoramento de forrageiras tropicais da UFT, cujos genitores estão descritos na Tabela 1. 


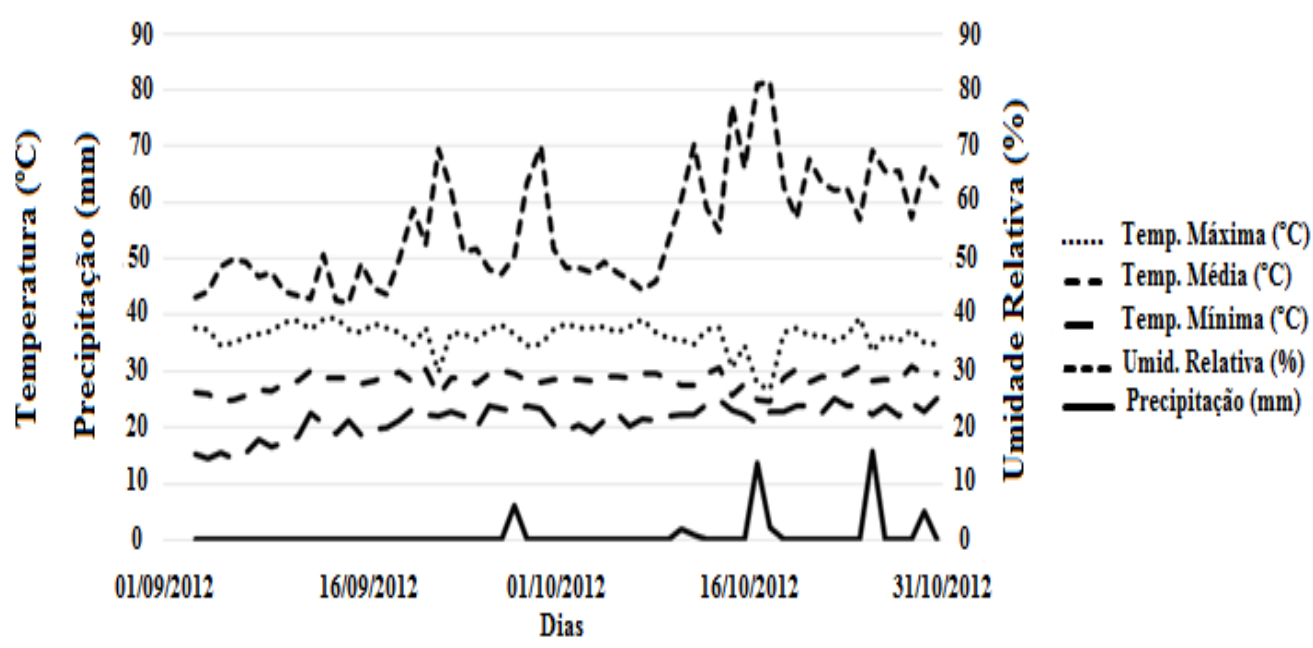

Figura 1. Umidade relativa, temperatura máxima, média e mínima do ar e precipitação, no período de setembro a outubro de 2012. UFT, Gurupi (TO) - (Fonte: Estação Meteorológica de Gurupi - TO).

Tabela 1. Descrição dos progenitores utilizados para formação dos híbridos experimentais.

\begin{tabular}{ccccccc}
\hline Cultivares & Empresa & Base genética & Cor do grão & $\begin{array}{c}\text { Textura do } \\
\text { grão }\end{array}$ & N T & Ciclo \\
\hline AG 2040 & Monsanto/Agroceres & HD & AM/AL & SMDURO & M & P \\
AG 8060 & Monsanto/Agroceres & HS & AL & DURO & A & P \\
AG 1051 & Monsanto/Agroceres & HD & AM & DENTADO & M/A & SMP \\
BM 2202 & Sementes Biomatrix & HD & AV & SMDENT & M/B & P \\
P 30F53Y & Pioneer Sementes & HS & AL & SMDURO & A & P \\
P 30F80 & Pioneer Sementes & HS & AL & DURO & A & P \\
TRUCK & Syngenta Seeds & HT & AL & SMDURO & M & P \\
IMPACTO & Syngenta Seeds & HS & AL & DURO & A & P \\
\hline
\end{tabular}

Base Genética: HS - Híbrido Simples; HD - Híbrido Duplo; HT - Híbrido Triplo. Cor de Grão: AL - Alaranjado; AM - Amarelo; AV - Avermelhado. Textura do Grão: SMDENT - Semidentado; SMDURO - Semiduro. N T (Nível Tecnológico): A - Alto; M Médio; B - Baixo. Ciclo: P - Precoce; SMP - Semiprecoce.

A capacidade de campo foi determinada por meio de um lisímetro, onde se matinha um saco plástico acoplado por baixo dos vasos para a coleta do excesso de água. Até o $5^{\circ}$ dia após emergência, os vasos foram mantidos à capacidade de campo. Após esse período, as irrigações foram realizadas diariamente através da pesagem dos vasos, mantendo-se o teor de água dentro das duas faixas estipuladas. Nos tratamentos de 20 e $80 \%$ da capacidade de vaso, os vasos foram mantidos com 3,1 e 3,4 kg, respetivamente.

Decorridos 20 dias da emergência, foram avaliadas as seguintes características: massa fresca da parte aérea (MFPA), massa seca da parte aérea (MSPA), massa fresca do sistema radicular (MFR), massa seca do sistema radicular (MSR), massa de raízes finas (MRF), massa de raízes grossas (MRG), utilizando uma balança de precisão; comprimento da raiz seminal (CRS), comprimento da parte aérea (CPA), utilizando trena; diâmetro do caule (DC), diâmetro da folha (DF), utilizando um paquímetro; volume de raiz (VR), utilizando uma proveta; conteúdo de água da parte aérea (CAPA), conteúdo de água na raiz (CAR), eficiência de utilização de água da parte aérea (EUAA), eficiência de utilização de água na raiz (EUAR).

Foi proposto para cálculo de eficiência de utilização da água a seguinte fórmula:

\section{EUA:(CANP/AAS) x MS}

EUA - Eficiência da utilização da água

CANP - Conteúdo de água na planta

AAS - Água aplicada no solo

MS - Massa seca

$\mathrm{Na}$ análise de divergência genética, em virtude do número de progenitores, foi realizada a análise de agrupamento pelo método de otimização proposto por Tocher (apud Rao, 1952), e o método hierárquico do vizinho mais próximo utilizando a distância generalizada de Mahalanobis (D2) como medida de dissimilaridade.

Utilizou-se, também, o critério de Singh (1981) para quantificar a contribuição relativa dessas características na divergência genética. Para realização das análises, utilizou-se o Aplicativo Computacional em Genética e Estatística - Programa Genes versão Windows (Cruz, 1997). 


\section{Resultados e Discussão}

A análise de agrupamento pelo método de Tocher, no ambiente com $20 \%$ da capacidade de campo, separou os 28 genótipos em 8 grupos dissimilares entre si (Tabela 2). No grupo 1, ficaram 18 genótipos geneticamente similares (64,28\% do total de genótipos), indicando que os possíveis cruzamentos destes entre si diminuem a possibilidade de obtenção de genótipos superiores. Nos grupos 2 e 3, com 2 genótipos $(7,14 \%$ do total de genótipos), fica representada a proximidade genética entre os indivíduos, pouco interessante para a condução de programas de melhoramento. Os genótipos $24,2,4,23$ e 6 ficaram isolados nos grupos 4, 5, 6, 7 e 8 , respectivamente.

A formação destes grupos é de fundamental importância para a escolha dos genitores, pois as novas combinações a serem estabelecidas devem ser baseadas na magnitude de suas dissimilaridades e no potencial per se dos progenitores (Almeida et al., 2011). Os genótipos reunidos em grupos mais distantes dão um indicativo de serem dissimilares, podendo ser considerados como promissores em cruzamentos artificiais. Cruz e Regazzi (2005) sugerem o não envolvimento de indivíduos do mesmo padrão de dissimilaridade nos cruzamentos, para não restringir a variabilidade genética e evitar reflexos negativos nos ganhos a serem obtidos pela seleção. Além de dissimilares, é necessário que os genitores associem média elevada e variabilidade nas características a serem melhoradas.

A análise de agrupamento pelo método de Tocher, no ambiente com $80 \%$ da capacidade de campo, separou os 28 genótipos em dois grupos (Tabela 3). No grupo 1 , ficaram 27 genótipos geneticamente similares $(96,42 \%$ do total de genótipos), indicando que os possíveis cruzamentos desses cultivares entre si diminuem a possibilidade de obtenção de genótipos superiores. O genótipo 1 ficou isolado no grupo 2.

Pode-se observar diferença na constituição dos grupos dissimilares mais distantes quando comparados os dois ambientes. Isso indica que embora haja genótipos com grande divergência genética entre si, a maioria é similar, o que, segundo Silva et al. (2011b), evidencia uma base genética estreita, mesmo em condições sem estresse. O mesmo foi observado por diversos autores em diferentes culturas: mostardaamarela (Vaishnava et al., 2006), pimenta e pimentão (Sudré et al., 2005), cana-de-açúcar (Silva et al., 2011a).

Vale ressaltar que o genótipo que apresentou maior dissimilaridade entre os demais, quando cultivado sob $20 \%$ CC, não apresentou o mesmo comportamento na condição de $80 \%$ CC, ficando agrupado juntamente com mais 27 genótipos num mesmo grupo. Tais resultados evidenciam a importância de se conduzir o programa de melhoramento genético nas condições em que se pretende obter superioridade.

Nas Tabelas 3 e 4 são apresentadas as estimativas de correlação fenotípica entre os caracteres avaliados no estudo. Os maiores valores de correlação fenotípica no tratamento com $20 \%$ CC (Tabela 3) foram obtidos entre as características massa fresca da parte aérea e conteúdo de água da parte aérea $(0,994)$ e entre massa fresca de raiz e eficiência de utilização de água da parte aérea $(0,999)$. Já no tratamento com $80 \%$ CC (Tabela 4), foram entre as características massa fresca da parte aérea e conteúdo de água da parte aérea $(0,997)$ e entre massa fresca de raiz e eficiência de utilização de água da parte aérea $(0,999)$. Observa-se que os maiores valores são significativos e idênticos estatisticamente, pois possuem relação quanto à absorção de água.

De certa forma, o desenvolvimento do sistema radicular está associado ao desenvolvimento da parte aérea. Através da correlação das características massa fresca de raiz e eficiência de utilização de água da parte aérea no ambiente $20 \%$ CC, observa-se que houve expressão considerável por alguns híbridos, pois a relação raiz/parte aérea varia em função das condições solo-planta-atmosfera e do estádio fenológico da cultura, o que mostra que no ambiente $80 \% \mathrm{CC}$ as plantas tiveram uma resposta já esperada.

Bergamaschi e Matzenauer (2014) mencionam que a temperatura é um fator importante no desenvolvimento da cultura do milho, atuando diretamente no seu metabolismo. Tojo Soler et al. (2005) demonstraram que é possível fazer simulação precisa da fenologia do milho. Assim, o acúmulo de graus-dias é empregado como parâmetro para estimar o crescimento de área foliar, ou seja, a partir do tempo térmico. Por isso, a influência direta da temperatura no metabolismo proporciona alta correlação entre o número final de folhas e a duração do período vegetativo.

No período do estudo, ocorreram dias quentes caracterizados por noites e dias quentes, com altas temperaturas. Com isso, espera-se que ocorra maior acumulação de graus-dia num menor período de tempo, o que justificaria a maior correlação entre as características massa seca da parte aérea e conteúdo de água na raiz nos dois ambientes (Tabela 4 e 5). Assim, a diferença entre os genótipos poderá estar relacionada com o ciclo da cultura pelo acúmulo de graus-dia. Nessas condições, a planta tende a acelerar o metabolismo, uma vez que ocorre aumento na taxa de respiração, consequentemente maior ganho de massa seca diária e uso da água. Galon et al. (2010) mencionam que elevadas temperaturas noturnas estão associadas com senescência e maturidade precoce, o que pode comprometer seriamente o rendimento dos grãos e, consequentemente, a produção. 
Tabela 2. Agrupamento pelo método de Tocher, com base na distância generalizada de Mahalanobis dos 28 genótipos experimentais de milho, considerando 15 características agronômicas em ensaio realizado com $20 \%$ da capacidade de campo.

\begin{tabular}{cc}
\hline Grupo & Cultivares \\
\hline I & $13 ; 14 ; 28 ; 17 ; 15 ; 21 ; 16 ; 18 ; 20 ; 22 ; 19 ; 8 ; 7 ; 26 ; 25 ; 27 ; 1 ; 5 ;$ \\
II & $9 ; 11 ;$ \\
III & $10 ; 12 ;$ \\
IV & $24 ;$ \\
V & $2 ;$ \\
VI & $4 ;$ \\
VII & $23 ;$ \\
VIII & 6 \\
\hline
\end{tabular}

Tabela 3. Agrupamento pelo método de Tocher, com base na distância generalizada de Mahalanobis dos 28 genótipos experimentais de milho, considerando 15 características agronômicas em ensaio realizado com $80 \%$ da capacidade de campo.

\begin{tabular}{cc}
\hline Grupo & Cultivares \\
\hline I & $11 ; 23 ; 26 ; 20 ; 16 ; 25 ; 27 ; 28 ; 22 ; 13 ; 5 ; 19 ; 7 ; 12 ; 2 ; 9 ; 10 ; 15 ; 21 ; 14 ; 24 ; 3 ; 6 ; 4 ; 17 ; 8 ;$ \\
II & 1 \\
\hline
\end{tabular}

Tabela 4. Coeficientes de correlação fenotípica entre 15 características agronômicas de 28 híbridos experimentais em ambiente com $20 \%$ da capacidade de campo.

\begin{tabular}{|c|c|c|c|c|c|c|c|c|c|c|c|c|c|c|}
\hline Caract. & MSPA & MFR & MSR & VR & MRF & MRG & CRP & DC & CPA & DF & CAPA & CAR & EUAA & EUAR \\
\hline MFPA & 0,788 & 0,666 & 0,777 & 0,594 & 0,518 & 0,774 & 0,427 & $-0,116$ & 0,772 & 0,464 & 0,994 & 0,954 & 0,65 & 0,622 \\
\hline MSPA & & 0,561 & 0,733 & 0,528 & 0,369 & 0,756 & 0,424 & $-0,230$ & 0,665 & 0,493 & 0,718 & 0,925 & 0,541 & 0,542 \\
\hline MFR & & & 0,887 & 0,872 & 0,956 & 0,903 & 0,315 & $-0,119$ & 0,543 & 0,075 & 0,656 & 0,67 & 0,999 & 0,973 \\
\hline MSR & & & & 0,738 & 0,765 & 0,916 & 0,458 & $-0,151$ & 0,611 & 0,256 & 0,751 & 0,812 & 0,869 & 0,894 \\
\hline VR & & & & & 0,838 & 0,783 & 0,381 & $-0,146$ & 0,481 & 0,045 & 0,581 & 0,609 & 0,874 & 0,869 \\
\hline MRF & & & & & & 0,739 & 0,128 & $-0,073$ & 0,391 & $-0,086$ & 0,522 & 0,501 & 0,962 & 0,937 \\
\hline MRG & & & & & & & 0,515 & $-0,17$ & 0,678 & 0,295 & 0,744 & 0,812 & 0,893 & 0,869 \\
\hline CRP & & & & & & & & $-0,002$ & 0,322 & 0,265 & 0,409 & 0,442 & 0,300 & 0,333 \\
\hline DC & & & & & & & & & $-0,237$ & $-0,338$ & $-0,091$ & $-0,142$ & $-0,115$ & $-0,073$ \\
\hline $\mathrm{CPA}$ & & & & & & & & & & 0,509 & 0,757 & 0,753 & 0,532 & 0,450 \\
\hline DF & & & & & & & & & & & 0,439 & 0,453 & 0,059 & 0,003 \\
\hline CAPA & & & & & & & & & & & & 0,919 & 0,641 & 0,609 \\
\hline CAR & & & & & & & & & & & & & 0,652 & 0,645 \\
\hline EUAA & & & & & & & & & & & & & & 0,969 \\
\hline
\end{tabular}

Características - MFPA: massa fresca da parte aérea; MSPA: massa seca da parte aérea; MFR: massa fresca de raiz; MSR: massa seca de raiz; VR: volume de raiz; MRF: massa de raiz fina; MRG: massa de raiz grossa; CRP: massa da raiz principal; DC: diâmetro de caule; CPA: comprimento da parte aérea; DF: diâmetro da folha; CAPA: conteúdo de água da parte aérea; CAR: conteúdo de água na raiz; EUAA: eficiência de utilização de água da parte aérea; EUAR: eficiência de utilização de água na raiz.

Tabela 5. Coeficientes de correlação fenotípica entre 15 características agronômicas de 28 híbridos experimentais em ambiente com $80 \%$ da capacidade de campo.

\begin{tabular}{|c|c|c|c|c|c|c|c|c|c|c|c|c|c|c|}
\hline Caract. & MSPA & MFR & MSR & VR & MRF & MRG & CRP & $\mathrm{DC}$ & CPA & DF & CAPA & CAR & EUAA & EUAR \\
\hline MFPA & 0,781 & 0,453 & 0,365 & 0,578 & 0,375 & 0,536 & 0,034 & 0,735 & 0,800 & 0,544 & 0,997 & 0,921 & 0,453 & 0,468 \\
\hline MSPA & & 0,690 & 0,612 & 0,420 & 0,645 & 0,638 & 0,231 & 0,687 & 0,589 & 0,527 & 0,729 & 0,945 & 0,686 & 0,704 \\
\hline MFR & & & 0,820 & 0,691 & 0,921 & 0,850 & 0,287 & 0,422 & 0,307 & 0,382 & 0,409 & 0,632 & 0,999 & 0,940 \\
\hline MSR & & & & 0,591 & 0,689 & 0,772 & 0,447 & 0,329 & 0,171 & 0,204 & 0,323 & 0,550 & 0,794 & 0,932 \\
\hline VR & & & & & 0,544 & 0,718 & 0,188 & 0,324 & 0,508 & 0,400 & 0,580 & 0,506 & 0,688 & 0,644 \\
\hline MRF & & & & & & 0,600 & 0,190 & 0,353 & 0,339 & 0,234 & 0,329 & 0,547 & 0,925 & 0,855 \\
\hline MRG & & & & & & & 0,385 & 0,497 & 0,286 & 0,513 & 0,506 & 0,656 & 0,843 & 0,820 \\
\hline CRP & & & & & & & & 0,303 & - & - & 0,008 & 0,145 & 0,270 & 0,394 \\
\hline DC & & & & & & & & & 0,53 & 0,385 & 0,718 & 0,747 & 0,422 & 0,415 \\
\hline CPA & & & & & & & & & & 0,401 & 0,802 & 0,666 & 0,313 & 0,280 \\
\hline DF & & & & & & & & & & & 0,529 & 0,547 & 0,390 & 0,284 \\
\hline CAPA & & & & & & & & & & & & 0,889 & 0,409 & 0,423 \\
\hline CAR & & & & & & & & & & & & & 0,629 & 0,654 \\
\hline EUAA & & & & & & & & & & & & & & 0,927 \\
\hline
\end{tabular}

Características - MFPA: massa fresca da parte aérea; MSPA: massa seca da parte aérea; MFR: massa fresca de raiz; MSR: massa seca de raiz; VR: volume de raiz; MRF: massa de raiz fina; MRG: massa de raiz grossa; CRP: massa da raiz principal; DC: diâmetro de caule; CPA: comprimento da parte aérea; DF: diâmetro da folha; CAPA: conteúdo de água da parte aérea; CAR: conteúdo de água na raiz; EUAA: eficiência de utilização de água da parte aérea; EUAR: eficiência de utilização de água na raiz. 
A amplitude das distâncias generalizadas de Mahalanobis $\left(\mathrm{D}^{2}\right)$ entre os genótipos no tratamento com $20 \%$ da capacidade de campo oscilou entre o valor máximo de 40,54 para o par de genitores 6 e 10 e o mínimo de 1,64 para os progenitores 13 e 14 (Tabela 6). Em termos genéticos, os progenitores com maior valor são mais divergentes, e os com menor valor, similares. $\mathrm{Na}$ sequência, as maiores magnitudes de divergência encontradas, em ordem decrescente, foram entre os pares de progenitores 6 e $16\left(\mathrm{D}^{2}=37,16\right), 6$ e $12\left(\mathrm{D}^{2}=\right.$ $36,69)$ e o par 6 e $9\left(D^{2}=36,47\right)$. Na sequência das menores estimativas de divergência encontram-se os pares 20 e $22\left(D^{2}=1,67\right), 15$ e $16\left(D^{2}=2,35\right)$ e 15 e 17 $\left(\mathrm{D}^{2}=2,42\right)$.

De acordo com Hallauer et al. (1995), devem-se observar os cruzamentos entre progenitores que apresentem médias elevadas e divergência ampla nas características de interesse. Contudo, se houver a necessidade de se optar entre genótipos com média de produção intermediária e ampla diversidade ou outros com alta produção e diversidade intermediária, deve prevalecer a última opção. Vale salientar o conhecimento das características qualitativas dos genótipos que originaram os híbridos avaliados, como também os valores médios das características comportamentais de interesses agronômicos direcionados ao ambiente de melhoramento.

Já no tratamento com $80 \%$ da capacidade de campo (Tabela 7), as medidas de dissimilaridade genética estimadas apresentaram magnitude (1,52 a 43,46), indicando a presença de variabilidade genética. A combinação entre os progenitores 1 e 17 foi a mais divergente $\left(D^{2}=43,46\right)$, seguida pela combinação 1 e 8 $\left(D^{2}=42,02\right)$. A menor distância foi obtida entre os genitores 11 e $23\left(D^{2}=1,52\right)$. Nota-se que as distâncias $\left(D^{2}\right)$ que possuem os menores valores de divergência incluem os genótipos agrupados no grupo I pelo método de Tocher (Tabelas 2 e 3).

A contribuição relativa das características na dissimilaridade genética dos híbridos experimentais de milho, nos dois ambientes, está apresentada na Tabela 8. Observa-se que as características apresentaram diferentes contribuições entre os ambientes. No ambiente com $20 \%$ CC, segundo o método de Singh (1981), as contribuições na divergência genética foram de massa fresca de raiz $(14,79 \%)$, massa de raiz fina $(13,37 \%)$ e eficiência de utilização de água da parte aérea $(13,43 \%)$ entre as demais características.

No ambiente com $80 \%$ CC, foram massa fresca de raiz $(13,82 \%)$, massa de raiz grossa $(16,86 \%)$, comprimento da parte aérea $(11,62 \%)$ e conteúdo de água na raiz $(11,69 \%)$ as características que apresentaram maior contribuição relativa na dissimilaridade genética, totalizando uma contribuição de $53,99 \%$, enquanto as restantes contribuíram com $46,01 \%$ (Tabela 7). Portanto, do mesmo modo que no ambiente com $20 \%$ CC, as características com maiores contribuições devem ser priorizadas na escolha de progenitores em programas de melhoramento, assim como as características relacionadas com a produção.

Tabela 6. Dissimilaridade entre híbridos de milho com $20 \%$ da capacidade de campo em relação a 15 características, com base na distância generalizada de Mahalanobis $\left(\mathrm{D}^{2}{ }_{\mathrm{ii}}\right)$.

\begin{tabular}{|c|c|c|c|c|c|c|c|c|c|c|c|c|c|c|c|c|c|c|c|c|c|c|c|c|c|c|c|}
\hline Cultivares & 2 & 3 & 4 & 5 & 6 & 7 & 8 & 9 & 10 & 11 & 12 & 13 & 14 & 15 & 16 & 17 & 18 & 19 & 20 & 21 & 22 & 23 & 24 & 25 & 26 & 27 & 28 \\
\hline 1 & 10,08 & 10,59 & 3,05 & 7,01 & 12,09 & 5,58 & 8,39 & 18,35 & 25,22 & 18,52 & 23,31 & 6,66 & 6,59 & 14,98 & 17,46 & 11,35 & 10,63 & 18,15 & 8,95 & 13,28 & 9,38 & 8,82 & 21,16 & 6,73 & 12,89 & 2,89 & 5,25 \\
\hline 2 & & 17,63 & 15,92 & 10,39 & 22,95 & 5,03 & 15,38 & 14,61 & 26,91 & 11,04 & 18,09 & 17,49 & 17,21 & 21,68 & 19,32 & 19,21 & 13,96 & 13,95 & 9,98 & 18,24 & 9,14 & 23,68 & 29,30 & 16,43 & 15,23 & 13,61 & 11,96 \\
\hline 3 & & & 14,58 & 8,69 & 19,43 & 10,81 & 6,96 & 20,41 & 23,70 & 16,43 & 23,70 & 9,42 & 10,43 & 14,98 & 16,91 & 12,61 & 15,67 & 15,52 & 7,95 & 11,11 & 7,47 & 11,65 & 21,99 & 15,39 & 9,75 & 12,27 & 13,41 \\
\hline 4 & & & & 15,05 & 13,97 & 7,66 & 8,88 & 24,38 & 29,98 & 24,07 & 27,60 & 9,17 & 8,57 & 18,97 & 19,71 & 14,21 & 13,92 & 21,54 & 11,78 & 13,96 & 11,77 & 15,07 & 23,29 & 10,33 & 16,05 & 6,97 & 7,77 \\
\hline 5 & & & & & 18,32 & 8,69 & 7,67 & 15,57 & 24,23 & 15,49 & 22,67 & 10,51 & 10,14 & 15,34 & 16,09 & 13,03 & 12,39 & 15,74 & 8,72 & 12,73 & 8,93 & 6,53 & 20,49 & 10,95 & 11,98 & 9,12 & 9,31 \\
\hline 6 & & & & & & 19,37 & 21,16 & 36,47 & 40,54 & 33,28 & 36,69 & 18,99 & 19,74 & 32,77 & 37,16 & 25,41 & 31,55 & 36,52 & 26,67 & 28,27 & 24,08 & 14,48 & 39,22 & 25,74 & 24,92 & 18,78 & 21,75 \\
\hline 7 & & & & & & & 5,69 & 17,83 & 25,76 & 13,09 & 19,62 & 6,55 & 6,40 & 12,31 & 10,55 & 10,16 & 7,89 & 8,28 & 3,99 & 6,82 & 3,51 & 17,41 & 19,21 & 9,72 & 9,01 & 6,85 & 5,25 \\
\hline 8 & & & & & & & & 15,93 & 20,71 & 15,23 & 20,68 & 5,88 & 5,86 & 10,67 & 8,55 & 8,73 & 8,41 & 9,35 & 4,12 & 4,77 & 4,31 & 13,70 & 11,52 & 8,54 & 7,06 & 9,38 & 6,32 \\
\hline 9 & & & & & & & & & 14,46 & 6,63 & 16,62 & 26,21 & 22,12 & 25,41 & 21,89 & 19,95 & 18,33 & 15,70 & 16,38 & 20,55 & 13,97 & 27,04 & 25,99 & 22,77 & 23,72 & 26,12 & 19,14 \\
\hline 10 & & & & & & & & & & 15,18 & 8,59 & 26,21 & 25,80 & 28,90 & 24,07 & 23,97 & 23,69 & 22,92 & 20,04 & 24,59 & 22,33 & 28,29 & 22,99 & 27,02 & 25,38 & 29,87 & 25,60 \\
\hline 11 & & & & & & & & & & & 8,05 & 20,83 & 17,36 & 17,29 & 15,29 & 15,12 & 18,23 & 10,52 & 14,64 & 15,67 & 12,26 & 27,93 & 24,74 & 25,55 & 13,44 & 25,24 & 17,06 \\
\hline 12 & & & & & & & & & & & & 21,53 & 21,00 & 22,42 & 18,83 & 19,76 & 22,26 & 19,61 & 19,59 & 23,41 & 22,20 & 30,24 & 18,69 & 24,56 & 14,62 & 26,20 & 18,95 \\
\hline 13 & & & & & & & & & & & & & 1,64 & 7,09 & 9,87 & 5,17 & 8,98 & 12,40 & 7,78 & 7,41 & 8,83 & 10,22 & 9,72 & 6,24 & 6,16 & 5,23 & 3,45 \\
\hline 14 & & & & & & & & & & & & & & 4,83 & 7,02 & 1,91 & 6,79 & 9,28 & 7,57 & 4,10 & 7,31 & 10,89 & 9,69 & 7,58 & 8,12 & 7,26 & 2,59 \\
\hline 15 & & & & & & & & & & & & & & & 2,35 & 2,42 & 5,21 & 6,16 & 8,49 & 5,64 & 9,42 & 22,58 & 8,68 & 10,87 & 6,50 & 13,35 & 5,44 \\
\hline 16 & & & & & & & & & & & & & & & & 4,37 & 3,31 & 3,22 & 5,47 & 3,63 & 7,13 & 27,27 & 7,16 & 11,19 & 7,61 & 15,52 & 6,06 \\
\hline 17 & & & & & & & & & & & & & & & & & 5,35 & 5,85 & 8,27 & 3,78 & 7,30 & 15,63 & 8,15 & 10,38 & 9,22 & 12,78 & 4,19 \\
\hline 18 & & & & & & & & & & & & & & & & & & 5,29 & 2,90 & 5,64 & 5,03 & 22,30 & 8,94 & 4,89 & 11,11 & 8,80 & 3,21 \\
\hline 19 & & & & & & & & & & & & & & & & & & & 5,26 & 3,59 & 3,49 & 28,26 & 13,66 & 16,12 & 10,90 & 19,50 & 9,25 \\
\hline 20 & & & & & & & & & & & & & & & & & & & & 4,57 & 1,67 & 19,08 & 12,70 & 6,67 & 8,13 & 7,70 & 5,33 \\
\hline 21 & & & & & & & & & & & & & & & & & & & & & 3,30 & 19,49 & 12,54 & 13,29 & 10,68 & 14,49 & 7,09 \\
\hline 22 & & & & & & & & & & & & & & & & & & & & & & 18,43 & 16,81 & 11,20 & 10,20 & 11,53 & 7,12 \\
\hline 23 & & & & & & & & & & & & & & & & & & & & & & & 24,49 & 15,98 & 20,23 & 12,74 & 14,60 \\
\hline 24 & & & & & & & & & & & & & & & & & & & & & & & & 8,53 & 10,51 & 16,91 & 7,53 \\
\hline 25 & & & & & & & & & & & & & & & & & & & & & & & & & 10,71 & 2,70 & 2,51 \\
\hline 26 & & & & & & & & & & & & & & & & & & & & & & & & & & 10,91 & 6,83 \\
\hline 27 & & & & & & & & & & & & & & & & & & & & & & & & & & & 4,16 \\
\hline
\end{tabular}


Tabela 7. Dissimilaridade entre híbridos de milho com $80 \%$ da capacidade de campo em relação a 15 características, com base na distância generalizada de Mahalanobis $\left(\mathrm{D}^{2}{ }_{\mathrm{ii}}\right)$.

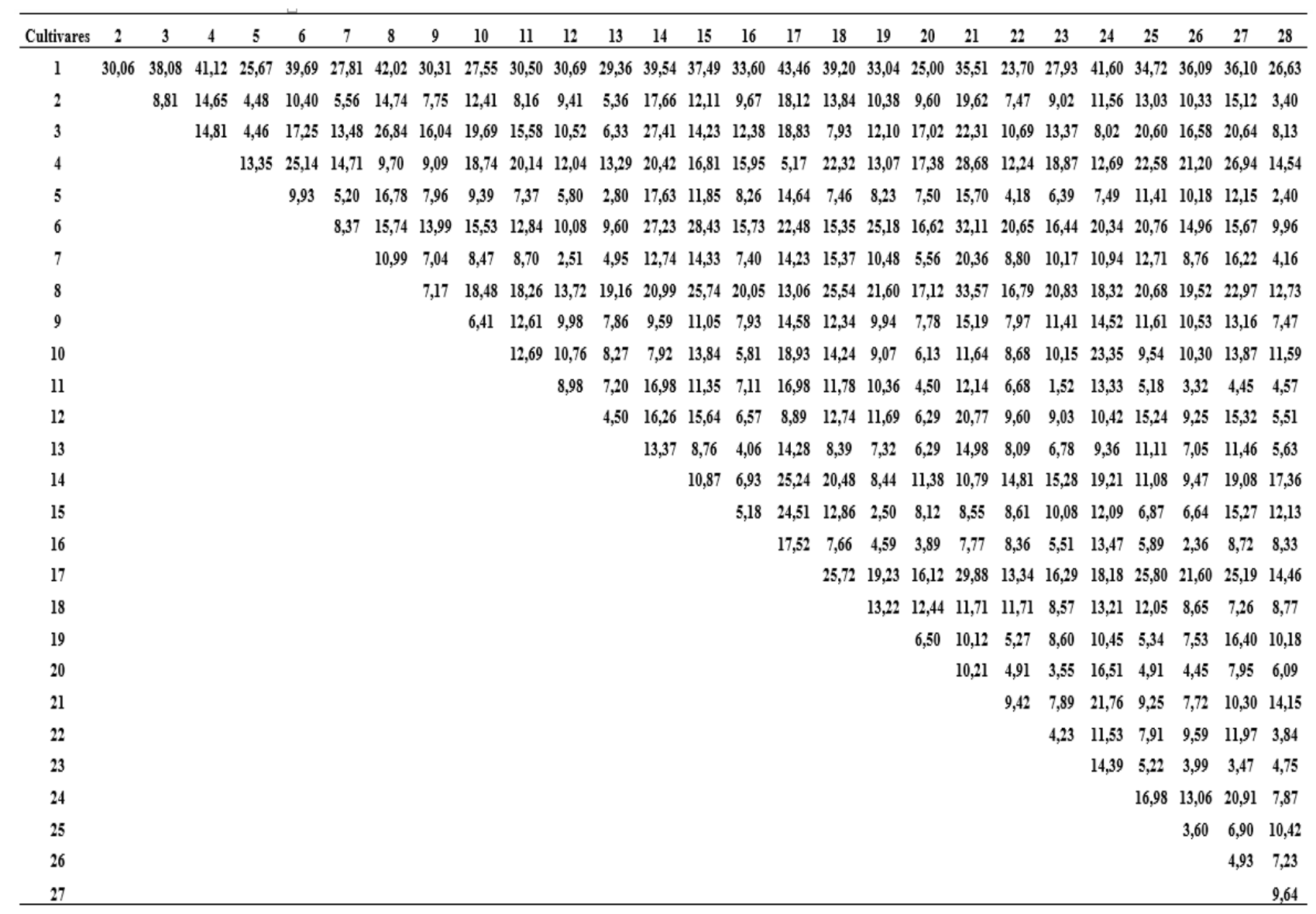

Tabela 8. Contribuição relativa em \%, considerando 15 características de 28 genótipos experimentais de milho, pelo método proposto por Singh (1981), em ensaio realizado com 20 e $80 \%$ da capacidade de campo.

\begin{tabular}{|c|c|c|c|c|}
\hline \multirow{2}{*}{$\begin{array}{c}\text { Ambiente } \\
\text { Características }\end{array}$} & \multicolumn{2}{|c|}{$20 \% \mathrm{CC}$} & \multicolumn{2}{|c|}{$80 \% \mathrm{CC}$} \\
\hline & S.J & Valor em \% & S.J & Valor em \% \\
\hline MFPA & 383,4 & 4,11 & 230,0 & 3,68 \\
\hline MSPA & 736,1 & 7,89 & 193,2 & 3,09 \\
\hline MFR & 1379,7 & 14,79 & 863,9 & 13,82 \\
\hline MSR & 122,7 & 1,32 & 331,2 & 5,29 \\
\hline VR & 371,3 & 4,00 & 323,8 & 5,18 \\
\hline MRF & 1247,1 & 13,37 & 91,7 & 1,47 \\
\hline MRG & 793,7 & 8,51 & 1053,8 & 16,86 \\
\hline CRP & 267,4 & 2,86 & 419,9 & 6,71 \\
\hline $\mathrm{DC}$ & 254,9 & 2,73 & 246,0 & 3,93 \\
\hline $\mathrm{CPA}$ & 750,6 & 8,05 & 726,3 & 11,62 \\
\hline DF & 433,2 & 4,64 & 143,1 & 2,28 \\
\hline CAPA & 921,1 & 9,87 & 424,1 & 6,78 \\
\hline CAR & 350,2 & 3,75 & 729,5 & 11,69 \\
\hline EUAA & 1252,1 & 13,43 & 293,6 & 4,69 \\
\hline EUAR & 59,4 & 0,64 & 180,01 & 2,88 \\
\hline
\end{tabular}

CC: capacidade de campo; MFPA: massa fresca da parte aérea; MSPA: massa seca da parte aérea; MFR: massa fresca de raiz; MSR: massa seca de raiz; VR: volume de raiz; MRF: massa de raiz fina; MRG: massa de raiz grossa; CRP: massa da raiz principal; DC: diâmetro de caule; CPA: comprimento da parte aérea; DF: diâmetro da folha; CAPA: conteúdo de água da parte aérea; CAR: conteúdo de água na raiz; EUAA: eficiência de utilização de água da parte aérea; EUAR: eficiência de utilização de água na raiz; S.J: método proposto por Singh (1981). 
Segundo Bergamaschi et al. (2006), a deficiência hídrica exerce uma redução sobre o crescimento do milho em função da área foliar. Nota-se, no ambiente com $20 \%$ CC, que a contribuição da característica comprimento da parte aérea foi significativa em conjunto com as restantes. Observa-se também, ao comparar os dois ambientes, que o comprimento da parte aérea do tratamento com $20 \%$ CC proporcionou menor contribuição do que a mesma característica no tratamento com $80 \% \mathrm{CC}$. Tal fato pode estar relacionado com a ocorrência de linhas de defesa à deficiência hídrica, onde a redução da área foliar ocorre devido à diminuição da turgescência das células e ao aumento da senescência das folhas (Taiz e Zeiger, 2009).

Além disso, o fechamento dos estômatos é um mecanismo de resposta, inicial e transitório, de resistência à seca, para evitar perdas de água: tem depois como consequência redução da assimilação de $\mathrm{CO}_{2}$, pois os estômatos fechados limitam a entrada de $\mathrm{CO}_{2}$ nas folhas (Pimentel, 2004). Por outro lado, altas temperaturas (sobretudo durante a noite) podem reduzir a assimilação líquida das plantas devido ao aumento das perdas por respiração, o que ocorre no ambiente com $80 \%$ CC. O crescimento radicular no solo está relacionado com a atividade fotossintética da planta, e, em condições de estresse, torna-se menos atingido que a expansão foliar (Flexas et al., 2004). Nestas condições, as plantas interrompem o crescimento da raiz principal para favorecer o crescimento de raízes secundárias e, posteriormente, das terciárias. Portanto, há um maior desenvolvimento de raízes finas, e consequentemente, um aumento da superfície de absorção, o que permite maior acumulação de assimilados distribuídos no sistema radicular.

No geral, quando comparados os ambientes, nota-se que os híbridos experimentais cultivados a $20 \%$ CC não apresentaram os mesmos comportamentos do que a $80 \%$ $\mathrm{CC}$, devido, principalmente, a diferentes contribuições das características em ambos os tratamentos. Tal fato está relacionado com a interação da água no sistema solo-planta-atmosfera. Quando cultivados em ambiente considerado como ideal (80\% CC), os híbridos experimentais obtiveram o mesmo desenvolvimento, evidenciando que o cultivo em condições de estresse hídrico proporciona diferentes expressões gênicas.

O critério de agrupamento adotado pelo método hierárquico do vizinho mais próximo estabelece que primeiramente seja formado um grupo de cultivares similares, e as distâncias dos demais são calculadas em relação aos grupos formados (Almeida et al., 2011). A aplicação desse método resulta num dendrograma, que permite identificar grupos homogêneos e tem como objetivo acumular as informações intra e intergrupos (Rotili et al., 2012). Por este método foi possível observar, quando os genótipos foram cultivados na condição de $20 \%$ CC, a formação de três grupos. A combinação dos cultivares 13 e 14 foi a que representou a menor distância $\left(D^{2}=1,64\right)$; já a maior distância foi constituída pelos cultivares 6 e $10\left(D^{2}=40,54\right)$, sendo considerada como $100 \%$ de distância para o estabelecimento do dendrograma (Figura 2).

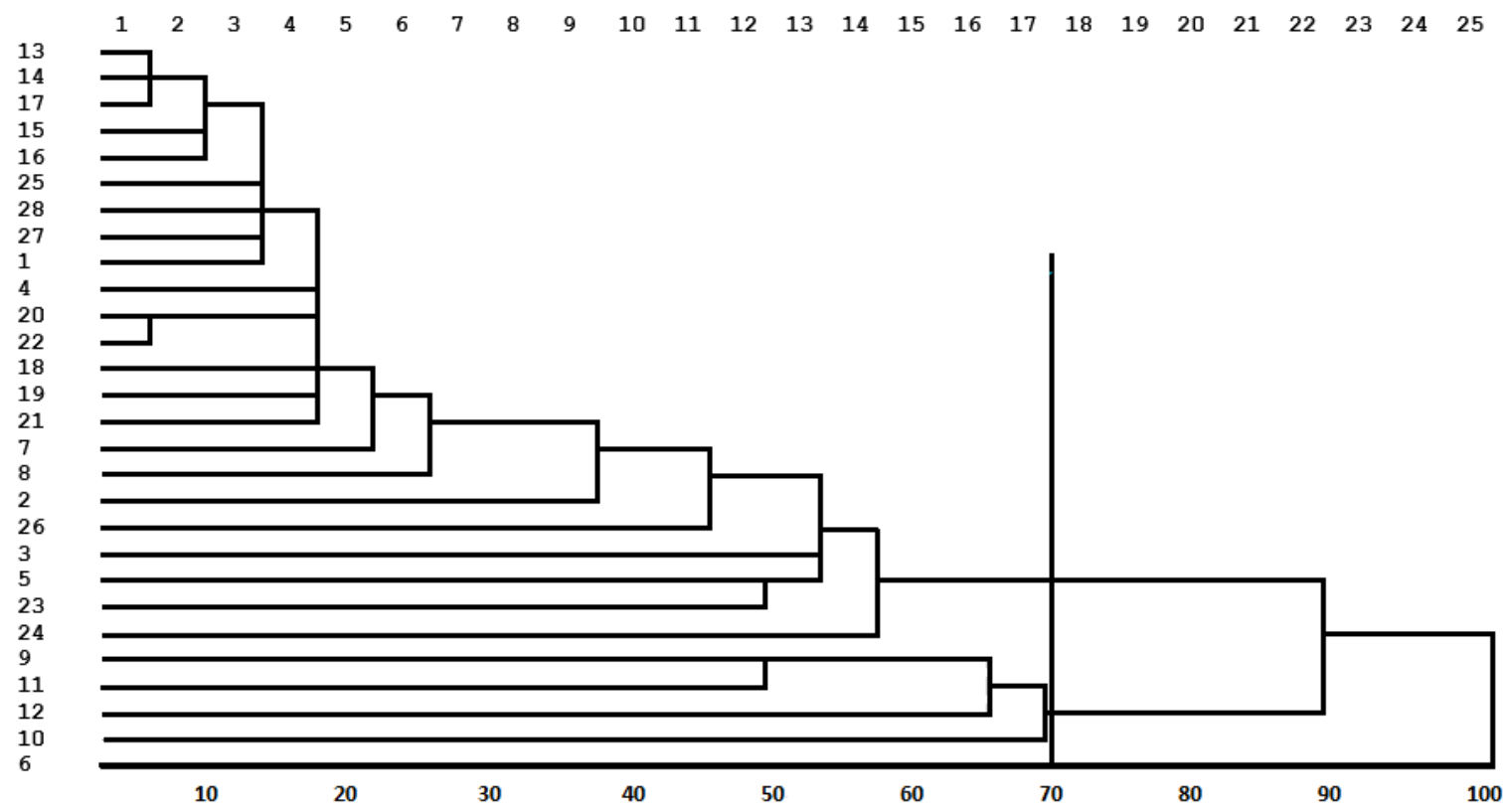

Figura 2. Dendrograma representativo da dissimilaridade genética dos 28 genótipos experimentais de milho, considerando 15 características obtidas pela técnica do vizinho mais próximo, utilizando a distância generalizada de Mahalanobis como medida de dissimilaridade em ensaio realizado com $20 \%$ da capacidade de campo. 
No eixo das abscissas ( $\mathrm{x}$ ) foram representadas as percentagens das distâncias entre os híbridos experimentais, e no eixo das ordenadas (y) foram representados os 28 híbridos experimentais. O grupo I foi constituído pelos acessos 13, 14, 17, 15, 16, 25, 28, $27,1,4,20,22,18,19,21,7,8,2,26,3,5,23$ e 24 ; o grupo II, pelos acessos 9, 11, 12 e 10; e o grupo III constituído apenas pelo acesso 6 .

Neste caso, o método hierárquico do vizinho mais próximo e o método de otimização de Tocher foram discordantes na partição dos grupos, o que está de acordo com os resultados encontrados por Yamaki et al. (2008). Contudo, os métodos são complementares e precisam ser analisados concomitantemente devido às informações acumuladas intra grupos do método hierárquico do vizinho mais próximo, com a visualização clara dos grupos distintos apresentados pelo método de otimização de Tocher.

Na Figura 3, observa-se a formação de dois grupos quando cultivados em condições ideais. Há uma concordância em relação aos componentes de cada grupo com o método de Tocher. Da mesma forma do que ocorreu com o método de Tocher, o método hierárquico do vizinho mais próximo também apresentou a maior porção dos acessos alocados no grupo 1. Resultados semelhantes foram observados por Zuin et al. (2007), que também verificaram que os métodos de Tocher e do vizinho mais próximo mostraram semelhança no padrão de agrupamento dos acessos.

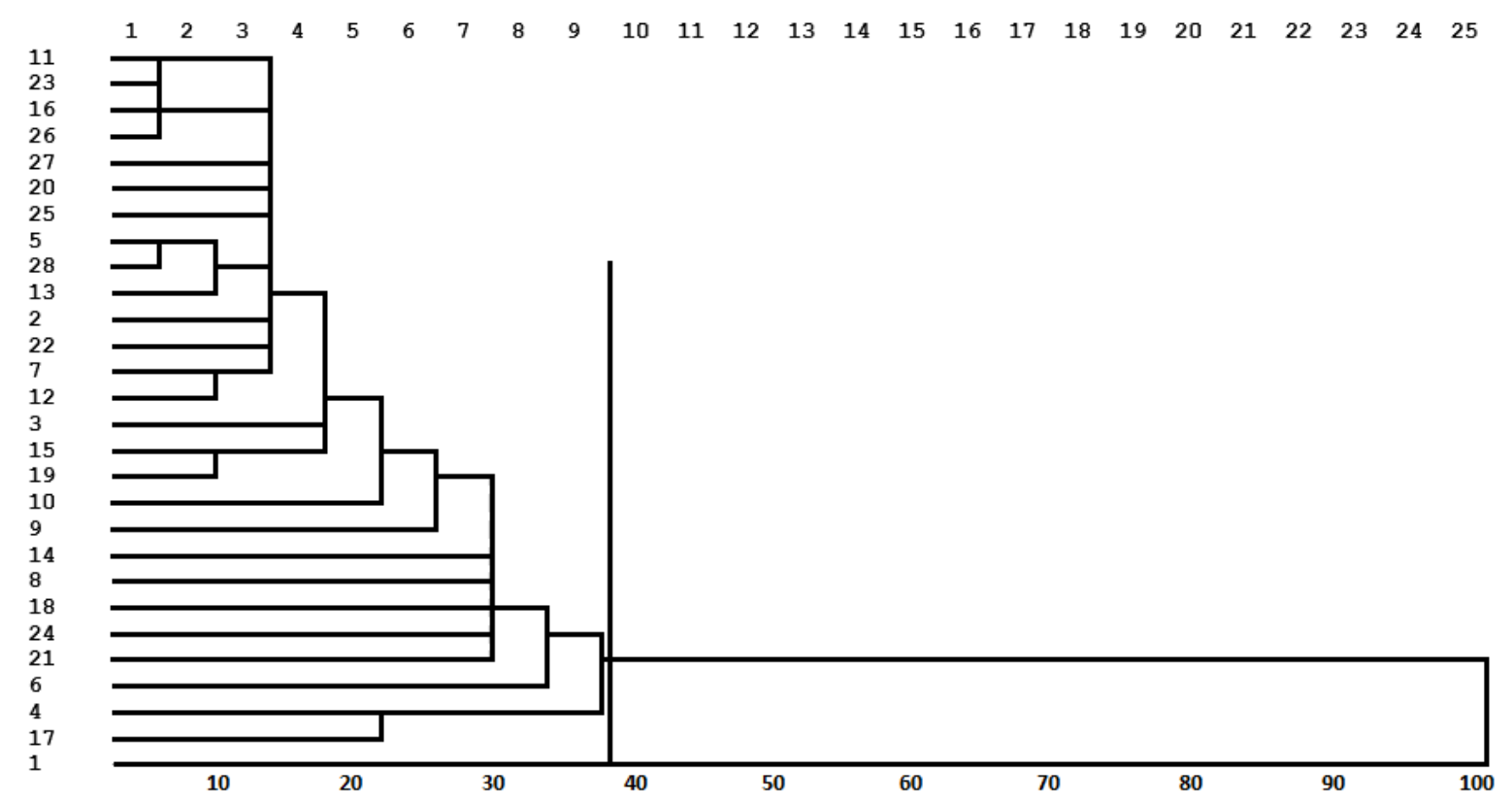

Figura 3. Dendrograma representativo da dissimilaridade genética dos 28 genótipos experimentais de milho, considerando 15 características obtidas pela técnica do vizinho mais próximo, utilizando a distância generalizada de Mahalanobis como medida de dissimilaridade em ensaio realizado com $80 \%$ da capacidade de campo.

\section{Conclusões}

Houve divergência genética entre os híbridos experimentais.

Os métodos de Tocher e vizinho mais próximo são complementares e precisam ser analisados concomitantemente devido às informações intra grupos do método hierárquico do vizinho mais próximo.

No ambiente de $20 \%$ CC são indicadas as combinações de cruzamentos entre os híbridos 6 e 10; 6 e $16 ; 6$ e 12 .

No ambiente de $80 \%$ CC são indicadas as combinações de cruzamentos entre os híbridos 1 e 17; 1 e $8 ; 1$ e 4 .

\section{Referências Bibliográficas}

Almeida, R.D., Peluzio, J.M., Afférri, F.S., 2011. Divergência genética entre cultivares de soja, sob condições de várzea irrigada, no sul do Estado Tocantins. Revista Ciência Agronômica, 42, 108-115.

Alves, V.M.C., Vasconcelos, C.A., Freire, F.M., Pitta, G.V.E., França, G.E., Rodrigues Filho, A., Araújo, J.M., Vieira, J.R., Loureiro, J.E., 1999. Milho, in: Ribeiro, A.C., Guimarães, P.T.G., Alvares, V.H. Recomendações para uso de corretivos e fertilizantes em Minas Gerais. Comissão de Fertilidade do Solo do Estado de Minas Gerais. Viçosa, [s.n.], 359 p.

Bänzinger, M., Edmeades, G.O., Beck, D., Bellon, M., 2000. Breeding for Drought and Nitrogen Stress Tolerance in Maize. From Theory to Practice. México, D.F.: Cimmyt, 68 p. 
Bergamaschi, H., Dalmago, G.A., Comiran, F., Bergonci, J.I., Muller, A.G., França, S., Santos, S.O., Radin, B., Bianchi, C.A.M., Pereira, P.G., 2006. Déficit hídrico e produtividade na cultura do milho. Brasília, Pesquisa Agropecuária Brasileira, 41, 243-249.

Bergamaschi, H., Matzenauer, R., 2014. O milho e o clima. Porto Alegre-RS.

Conab. Companhia Nacional de Abastecimento, 2018. Ministério da Agricultura, Pecuária e Abastecimento. Acompanhamento de Safra Brasileira, Safra 2017/2018. Brasília, Ministério da Agricultura, Pecuária e Abastecimento, $20 \mathrm{p}$.

Cruz, C.D., 1997. Programa Genes: Aplicativo computacional em genética e estatística, Viçosa-MG, UFV.

Cruz, C.D., Regazzi, A.J., 2005. Modelos biométricos aplicados ao melhoramento genético. Viçosa-MG, UFV.

Domingues, E.P., Magalhães, A.S., Ruiz, R.M., 2011. Cenários de Mudanças Climáticas e Agricultura no Brasil: Impactos Econômicos na Região Nordeste. Documentos técnico-científicos. Belo Horizonte-MG, p. 229-246.

Dotto, M.A., Afférri, F.S., Peluzio, J.M., Melo, A.V., Carvalho, E.V., 2010. Divergência genética entre cultivares comerciais de milho em baixas altitudes no Tocantins, safra 2007/2008. Revista Ciência Agronômica, 41, 630-637.

Flexas, J., Bota, J., Loreto, F., Cornic, G., Sharkey, T.D., 2004. Diffusive and metabolic limitations to photosynthesis under drought and salinity in $\mathrm{C}_{3}$ plants. Plant Biology, 6, 269279.

Galon, L., Tironi, S.P., Rocha, A.A., Soares, E.R., Concenço, G., Alberto, C.M., 2010. Influência dos fatores abióticos na produtividade da cultura do milho. Revista Trópica: Ciências Agrárias e Biológicas, 4, 18.

Gholamin, R., Khayatnezhad, M., 2011. The effect of end season drought stress on the chlorophyll contente, chlorophyll fluorescence parameters and yield in maize cultivars. Science Research and Essays, 6, 5351-5357.

Hallauer, A.R., Carena, M.J., Miranda Filho, J.B., 1995. Quantitative genetics in maize breeding. Handbook of Plant Breeding. New York: Springer. Iowa State University Press, 468.

Pimentel, C., 2004. A relação da planta com a água. Seropédica-RJ: UF Rural RJ.

Rahman, M.U., Gul, S., Ahmad, I., 2004. Effects of water stress on growth and photosynthetic pigments of corn (Zea mays L.) cultivars. International Journal of Agricultural \& Biology, 6, 4409-4411.

Rao, R.C., 1952. Advanced statistical methods in biometric research. New York: J. Wiley.

Rotili, E.A., Cancellier, L.L., Dotto, M.A., Peluzio, J.M., Carvalho, V.E., 2012. Divergência genética em genótipos de milho, no Estado do Tocantins. Revista Ciência Agronômica, $43,516-521$

Silva, G.C., Oliveira, F.J., Anunciação Filho, C.J., Neto, D.E.S., Melo, L.J.O.T., 2001a. Divergência genética entre genótipos de cana de-açúcar. Revista Brasileira de Ciências Agrárias, 6, 52-58.

Silva, M.A., Santos, C.M., Labate, C.A., Guidetti-Gonzalez, S., Borges, J.S., Ferreira, L.C., Delima, R.O., Fritsche-Neto, R., 2001b. Melhoramento para eficiência no uso da água, in: Fritsche-Neto, R., Borém, A., (Ed.), Melhoramento de plantas para condições de estresses abióticos. Visconde do Rio Branco-MG, Suprema, 127-149.

Singh, D., 1981. The relative importance of characters affecting genetic divergence. The Indian Journal of Genetics and Plant Breeding, 41, 237-245.

Sudré, C.P., Rodrigues, R., Riva, E.M., Karasawa, M., Amaral Júnior, A.T., 2005. Divergência genética entre acessos de pimenta e pimentão utilizando técnicas multivariadas. Horticultura Brasileira, 23, 22-27.

Taiz, L., Zeiger, E., 2009. Fisiologia Vegetal, quarta ed. Porto Alegre-RS.

Tojo Soler, C.M., Sentelhas, P.C., Hoogenboom, G., 2005. Thermal time for phonological development of four maize hybrids grown off-season in a subtropical environment. Journal of Agricultural Science, 143, 169-182.

Vaishnava, A., Sachan, J.N., Tewari, S.K., 2006. Genetic divergence for important quantitative traits in Indian mustard (Brassica juncea (1.) czern and coss). Agricultural Science Digest, 26, 269-272.

Yamaki, M., Menezes, G.R.O., Teixeira, R.B., Barbosa, L., Paiva, A.L.C., Torres, R.A., 2008. Divergência genética entre linhagens de matrizes de corte por meio de análise de agrupamento. Revista Brasileira de Zootecnia, 37, 829- 833.

Zuin, G.C., Vidigal Filho, P.S., Kvitschal, M.V., Vidigal, M.C.G., Coimbra, G.K., 2007. Utilização de descritores morfo-agronômicos na quantificação da divergência genética entre acessos de mandioca de mesa. Revista Raízes e Amidos Tropicais, 3, 4 . 